\title{
Fontes alternativas à ureia no fornecimento de nitrogênio para o arroz irrigado
}

\author{
Alternative sources of supply in the urea nitrogen for rice production
}

\section{Enio Marchesan ${ }^{\mathrm{I}}$ Mara Grohs $^{\mathrm{I}^{*}}$ Dâmaris Sulzbach Santos ${ }^{\mathrm{I}}$ Tiago Constante Formentini ${ }^{\mathrm{I}}$ Leandro Souza da Silva ${ }^{\text {II }}$ Gerson Meneghetti Sarzi Sartori ${ }^{I}$ Rafael Bruck Ferreira $^{\mathrm{I}}$}

\section{RESUMO}

A ureia é a principal fonte de $N$ usada na agricultura, mas apresenta grandes perdas em arroz irrigado por alagamento. $O$ objetivo deste trabalho foi avaliar a eficiência de fontes de $N$ alternativas à ureia para utilização pelo arroz irrigado aplicadas em diferentes estádios de desenvolvimento da planta através da quantificação da volatilização de $\mathrm{N}_{-} \mathrm{NH}_{3}$ e de parâmetros agronômicos. $\mathrm{O}$ experimento foi realizado em campo nos anos agrícolas 2007/ 08 e 2008/09. O delineamento experimental foi de blocos ao acaso com quatro repetições. Os tratamentos foram compostos de diferentes fontes de $N$ aplicados na semeadura, no perfilhamento e no estádio de diferenciação floral: testemunha sem aplicação de $N$, ureia, ureia +inibidor de urease, duas fontes de $N$ líquido ( $N-28$ e $N$-30), sulfato de amônio e ureia + enxofre. Nas duas safras, a volatilização de $\mathrm{N}-\mathrm{NH}_{3}$ na semeadura foi praticamente insignificante, enquanto no estádio V4 a fonte que menos volatilizou foi o sulfato de amônio. A resposta em produtividade variou entre os anos, provavelmente em função da disponibilidade de $N$ no solo e aspectos climáticos. Quando vantajoso economicamente, o uso do inibidor de urease e o sulfato de amônio proporcionam produtividades semelhantes à fonte ureia.

Palavras-chave: volatilização, inibidor de urease, sulfato de amônio, fertilizantes fluidos.

\section{ABSTRACT}

Urea is the main source of $N$ used in agriculture, but has large losses in irrigated rice. The objective of this study was to evaluate the efficiency of $N$ sources alternative to urea for use by rice applied at different stages of plant development through the quantification of $\mathrm{N}-\mathrm{NH}_{3}$ and agronomic parameters. The experiment was conducted in the field in the agricultural years 2007/08 and 2008/09. The experimental design was randomized blocks with four replications. The treatments consisted of different $N$ sources applied at seeding, tillering and at the stage of floral differentiation: control without $N$, urea, urea + urease inhibitor, two sources of liquid $N(N-28$ and $N$-30) ammonium sulfate and urea + sulfur. In both seasons, the volatilization of $\mathrm{N}-\mathrm{NH}_{3}$ at seeding was almost negligible, whereas in the V4 stage, the source that was less volatilized was the ammonium sulfate. Yield response varied among years, probably due to the availability of $N$ in the soil and climatic aspects. When economically advantageous, the use of urease inhibitor and ammonium sulfate provide yields similar to urea supply.

Key words: volatilization, urease inhibitor, ammonium sulfate, fertilizer fluids.

\section{INTRODUÇÃO}

Apesar dos avanços recentes em relação à produtividade média obtida com o arroz irrigado no Brasil, ainda há uma lacuna entre aquela obtida pelo produtor e o potencial produtivo das variedades. Entre as práticas utilizadas para a obtenção de elevadas produtividades, a aplicação do nitrogênio $(\mathrm{N})$ é determinante em arroz (CHATURVEDI, 2005). O N pode ser fornecido à planta através do ar ( $\mathrm{N}$ atmosférico), pelo solo e através de fertilizantes industriais e orgânicos. Entre as fontes industriais de N, a ureia é a mais utilizada, pois possui maior concentração de $\mathrm{N}$, menor preço relativo e menor poder acidificante do solo,

IDepartamento de Fitotecnia, Universidade Federal de Santa Maria (UFSM), Av. Roraima, 1000, 97105-900, Santa Maria, RS, Brasil. E-mail: maragrohs@yahoo.com.br. *Autor para correspondência.

IIDepartamento de Solos, UFSM, Santa Maria, RS, Brasil. 
quando comparada as outras fontes. Porém, possui elevado potencial de perdas (NORMAN et al., 2005) que, segundo MARTHA JÚNIOR et al. (2004), podem atingir até $80 \%$ do $\mathrm{N}$ aplicado. Com isso, nos últimos anos, a indústria tem se voltado à produção de fontes alternativas a ureia, as quais sejam menos propensas a perdas, seja pela inibição da urease (ureia recoberta com inibidor de urease), seja pela forma como o $\mathrm{N}$ é apresentado nos fertilizantes minerais, por exemplo, na forma de amônio em grânulo (sulfato de amônio) ou até mesmo na forma de fertilizantes líquidos que possuem maior facilidade em penetrar no solo ou em serem absorvidos pela planta.

Em vista do exposto, o trabalho teve por objetivo avaliar a volatilização de $\mathrm{N}-\mathrm{NH}_{3}$ e o desempenho agronômico do arroz irrigado em relação à utilização de diferentes fontes de fornecimento de $\mathrm{N}$ alternativas à ureia, aplicadas em diferentes estádios de desenvolvimento das plantas.

\section{MATERIAL E MÉTODOS}

Os experimentos foram desenvolvidos nas safras 2007/08 e 2008/09 na Universidade Federal de Santa Maria, Rio Grande do Sul, em solo classificado como Planossolo Háplico eutrófico arênico, pertencente à unidade de mapeamento Vacacaí (EMBRAPA, 2006), com as seguintes características:
$\mathrm{pH}_{\text {agua }}(1: 1)=5,0 ; \mathrm{P}_{(\text {Mehlich-1) }}=11,8 \mathrm{mg} \mathrm{dm}^{-3} ; \mathrm{K}_{\text {(Mehlich-1) }}=$ $76 \mathrm{mg} \mathrm{dm}^{-3}$; M.O. $=2,4 \% ; \mathrm{Ca}=4,8 \mathrm{cmol}_{\mathrm{c}} \mathrm{dm}^{-3} ; \mathrm{Mg}=$ $1,6 \mathrm{cmol}_{\mathrm{c}} \mathrm{dm}^{-3} ; \mathrm{Al}=0,5 \mathrm{cmol}_{\mathrm{c}} \mathrm{dm}^{-3} \mathrm{e}$ argila $=25 \%$. O delineamento experimental foi de blocos ao acaso com 13 tratamentos e quatro repetições. Os tratamentos foram compostos da utilização de fontes de nitrogênio (N) com aplicação em diferentes estádios do arroz: na semeadura, em V4, variando a última aplicação na diferenciação do primórdio floral (R1) (Tabela 1).

A cultivar utilizada foi a 'IRGA 417' na densidade de $110 \mathrm{~kg}$ de sementes $\mathrm{ha}^{-1}$ nas duas safras. A adubação, por ocasião da semeadura, foi de $60 \mathrm{~kg} \mathrm{ha}^{-1}$ de $\mathrm{P}_{2} \mathrm{O}_{5}$ e $90 \mathrm{~kg} \mathrm{ha}^{-1}$ de $\mathrm{K}_{2} \mathrm{O}$. As unidades experimentais mediram 4,0 x 2,87m $\left(11,48 \mathrm{~m}^{2}\right)$ e a área útil para estimativa da produtividade de grãos foi de 3,0 x 1,19m $\left(3,57 \mathrm{~m}^{2}\right)$. Os demais tratos culturais foram realizados conforme recomendação da pesquisa para o arroz irrigado (SOSBAI, 2007).

As avaliações de perdas de $\mathrm{N}$ por volatilização de amônia $\left(\mathrm{N}-\mathrm{NH}_{3}\right)$ foram realizadas com coletores e procedimentos conforme ARAÚJO et al. (2006). As avaliações foram realizadas às 10, 24, 34, 48, 72 e 96 horas após a aplicação da fonte nitrogenada por ocasião da semeadura e às $10,24,34,48$ e 72 horas após a aplicação do fertilizante nitrogenado no perfilhamento, sendo o $\mathrm{N}-\mathrm{NH}_{3}$ determinado posteriormente através de metodologia descrita por TEDESCO(1995).

Tabela 1 - Relação das fontes de nitrogênio, com suas respectivas garantias, aplicadas em diferentes estádios da cultura do arroz irrigado. Santa Maria, 2010.

\begin{tabular}{|c|c|c|c|c|c|}
\hline \multirow{3}{*}{ Tratamentos } & \multirow{3}{*}{ Fontes } & \multirow[t]{3}{*}{ Garantia de N } & \multicolumn{3}{|c|}{-----------------Estádio de aplicação de N---------------- } \\
\hline & & & $\mathrm{S}^{1}$ & $\mathrm{~V} 4^{2}$ & $\mathrm{R} 1$ \\
\hline & & & \multicolumn{3}{|c|}{---1----'Quantidade de N $\left(\mathrm{kg} \mathrm{ha}^{-1}\right)$} \\
\hline $\mathrm{T} 1$ & Testemunha & - & - & - & - \\
\hline $\mathrm{T} 2$ & $\mathrm{~N}-30$ & 30 & 15 & 70 & - \\
\hline $\mathrm{T} 3$ & Inibidor de urease & 45 & 15 & 70 & 30 \\
\hline $\mathrm{T} 4$ & Ureia & 45 & 15 & 70 & 30 \\
\hline T5 & Sulfato de Amônio & 21 & 15 & 70 & 30 \\
\hline T6 & Ureia+ S & 21 & 15 & 70 & 30 \\
\hline $\mathrm{T} 7$ & $\mathrm{~N}-30$ & 30 & 15 & 70 & 30 \\
\hline $\mathrm{T} 8$ & Inibidor de urease & 45 & 15 & 70 & - \\
\hline T9 & Ureia & 45 & 15 & 70 & - \\
\hline $\mathrm{T} 10$ & Sulfato de Amônio & 21 & 15 & 70 & - \\
\hline $\mathrm{T} 11$ & Ureia $+S$ & 45 & 15 & 70 & - \\
\hline $\mathrm{T} 12$ & $\mathrm{~N}-28$ & 28 & 15 & 70 & - \\
\hline $\mathrm{T} 13$ & $\mathrm{~N}-28$ & 28 & 15 & 70 & 30 \\
\hline
\end{tabular}

${ }^{1}$ Semente não embebida de água; as fontes foram incorporadas ao solo.

${ }^{2}$ Formação do colar na $4^{a}$ folha do colmo principal; as fontes foram aplicados em superfície.

${ }^{3}$ Formação das ramificações da panícula; as fontes foram aplicados sobre lâmina de água. 
Aos 10 dias após a emergência (DAE), foi demarcado um metro de linha de semeadura em cada unidade experimental, onde se realizou o desbaste das plantas, resultando em média 330plantas. $\mathrm{m}^{-2}$. Nessa área, realizou-se a contagem do número de colmos planta $^{-1}$ aos 25 e 52 DAE, para as duas safras, e o número de panículas, por ocasião da pré-colheita, aos $115 \mathrm{DAE}$. Na mesma ocasião, avaliou-se a estatura de 10 plantas escolhidas ao acaso. Ainda nesse local, simultaneamente, coletaram-se 10 panículas consecutivas escolhidas ao acaso, das quais foram determinados o número de grãos por panícula, a esterilidade de espiguetas e a massa de mil grãos.

O monitoramento do estado nutricional da cultura, em relação ao N, foi realizado através do índice de clorofila, estimado através da leitura do clorofilômetro (modelo SPAD-502) na última folha completamente expandida, em três posições da folha, em três plantas por parcela, aos 54 e 82DAE, nas duas safras. A produtividade de grãos foi determinada colhendo-se manualmente as panículas da área útil das parcelas quando os grãos atingiram umidade média de $20 \%$. Estas foram trilhadas e, posteriormente, determinou-se a massa dos grãos e a umidade foi corrigida para $13 \%$.
As variáveis determinadas foram submetidas à análise de variância, através do teste $\mathrm{F}, \mathrm{e}$ as médias foram comparadas pelo teste de Tukey $(\mathrm{P} \leq 0,05)$.

\section{RESULTADOS E DISCUSSÃO}

Volatilização de amônia $\left(\mathrm{N}^{-\mathrm{NH}_{3}}\right)$

O fluxo de volatilização de amônia ( $\left.\mathrm{N}-\mathrm{NH}_{3}\right)$ logo após a semeadura, nas safras 2007/08 e 2008/09, foi semelhante entre as fontes (Figura 1), porém as quantidades perdidas variaram entre os anos. Essa semelhança é explicada por todas as fontes terem sido incorporadas ao solo por ocasião da semeadura, favorecendo a adsorção de amônio $\left(\mathrm{NH}_{4}^{+}\right)$às cargas negativas e, consequentemente, reduzindo as perdas de $\mathrm{N}-\mathrm{NH}_{3}$ por volatilização (MARTHA JÚNIOR et al., 2004).

$\mathrm{Na}$ segunda safra, as perdas de $\mathrm{N}$ por volatilização de $\mathrm{N}-\mathrm{NH}_{3}$ foram significativamente menores que a primeira safra. Como o manejo de aplicação foi o mesmo para as duas safras e não ocorreu nenhuma precipitação no período de avaliação, a diferença na quantidade volatilizada provavelmente está atrelada à umidade do solo em que o experimento

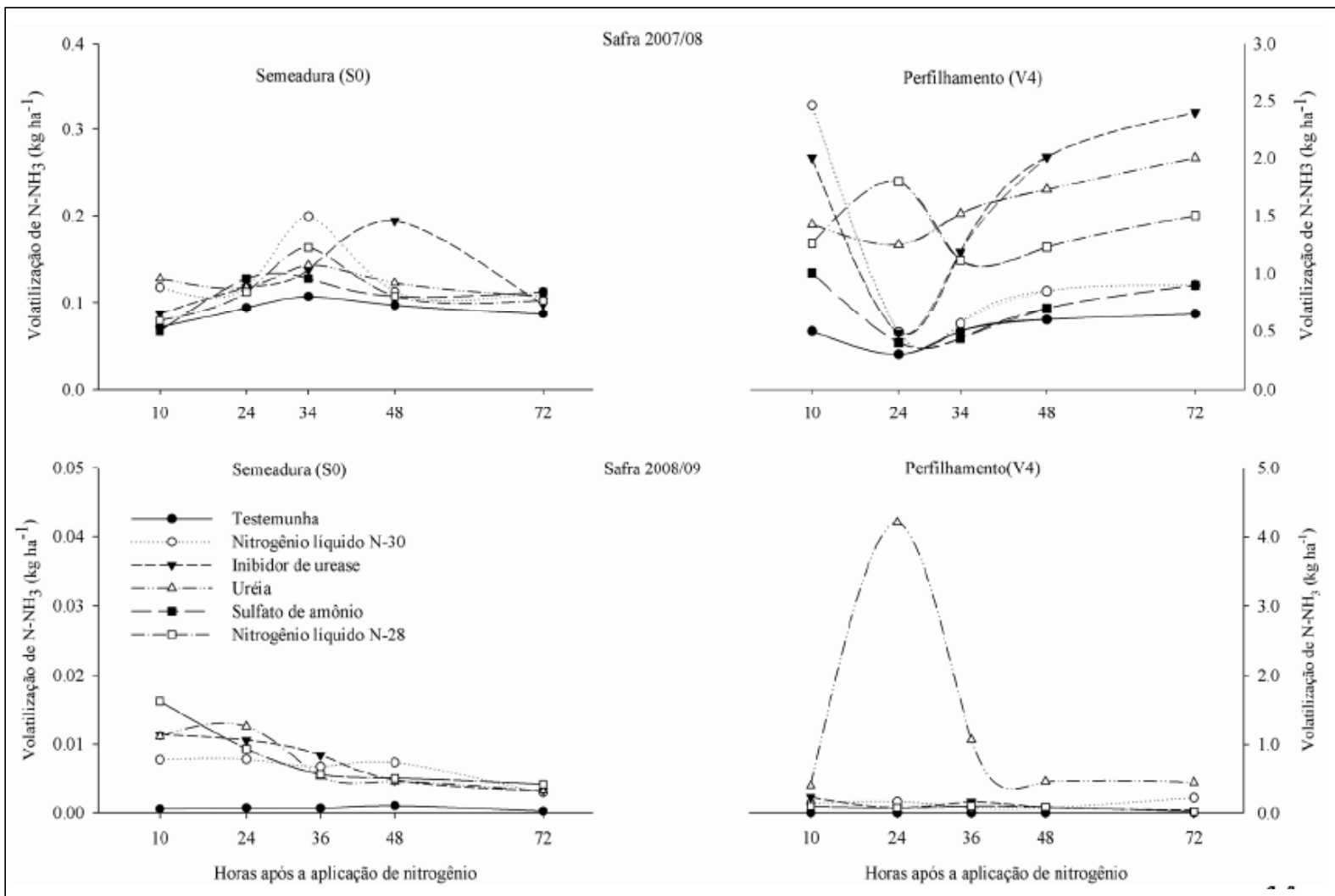

Figura 1 - Fluxo de $\mathrm{N}-\mathrm{NH}_{3}$ em função da fonte de nitrogênio utilizada no momento da semeadura (estádio S0) e no perfilhamento (estádio V4) durante 72 horas após a aplicação na cultura do arroz irrigado. Santa Maria, 2010. 
foi semeado. Os maiores picos de volatilização ocorrem após 36 a 48 horas da aplicação do fertilizante quando o solo encontra-se em uma condição de úmido a saturado em decorrência da rápida hidrólise (DUARTE et al., 2007). Quando o solo está inicialmente úmido, ele também está secando continuamente e perdendo $\mathrm{H}_{2} \mathrm{O}$. Isso força a reação de formação da amônia $\mathrm{NH}_{4}+$ $\mathrm{OH} \Leftrightarrow \mathrm{H}_{2} \mathrm{O}+\mathrm{NH}_{3 \text { (gás) }}$ para o lado direito da equação, produzindo mais $\mathrm{NH}_{3}$ (HARRELL, 2007), o qual é perdido.

As perdas por volatilização em função da aplicação do N no estádio do perfilhamento (V4) estão representadas na figura 1. Para a safra 2007/08, o pico de volatilização para a maioria dos fertilizantes ocorreu 10 horas após a aplicação das fontes, possivelmente em função da ocorrência de uma precipitação de $40 \mathrm{~mm}$ poucas horas após a aplicação dos tratamentos. $\mathrm{O}$ umedecimento do solo, imediatamente após a aplicação das fontes nitrogenadas, é mais importante do que a condição de umidade do solo no momento da aplicação (LARA CABEZAS et al., 1997) e a água somente diminui a volatilização do $\mathrm{N}^{-\mathrm{NH}_{3}}$ se for suficiente para diluir a concentração de oxidrilas (OH-) ao redor dos grânulos de ureia. Do contrário, a volatilização é favorecida por estimular a hidrólise do fertilizante.

$\mathrm{O}$ sulfato de amônio foi a fonte que apresentou menor volatilização de $\mathrm{N}-\mathrm{NH}_{3}$, com perdas de $2,5 \mathrm{~kg} \mathrm{ha}^{-1}$ de $\mathrm{N}$, correspondendo a $3 \%$ dos $70 \mathrm{~kg} \mathrm{ha}^{-1}$ de $\mathrm{N}$ aplicados no perfilhamento, em comparação com a ureia e ureia+inibidor de urease, que foram as fontes que mais volatilizaram $\mathrm{N}-\mathrm{NH}_{3}$, com perdas de $8,4 \%$ e $8,1 \%$ da quantidade de $\mathrm{N}$ aplicada no perfilhamento do arroz. A maior eficiência do sulfato de amônia é em decorrência do $\mathrm{N}$ estar na forma de $\mathrm{NH}_{4}{ }^{+} \mathrm{em} \mathrm{pH}$ inferior a 7,0, diferente da ureia que precisa ser hidrolisada pela enzima urease, gerando carbonato de amônio que eleva o pH, favorecendo a reação do $\mathrm{NH}_{4}{ }^{+}+\mathrm{OH}^{+}$e, consequentemente, a liberação da amônia (COELHO et al., 2007). Entre as fontes líquidas, o N-30 demonstrou um comportamento muito semelhante ao sulfato de amônio, provavelmente pela sua composição ser baseada na forma de $\mathrm{NH}_{4}{ }^{+}$. Já a fonte $\mathrm{N}-28$ apresentou um pico de volatilização às 24 horas após a aplicação com perdas equivalentes à ureia e ao inibidor de urease, em função, provavelmente, de possuir ureia em sua composição.

\section{Comportamento agronômico} Safra 2007/08

Os tratamentos que receberam as fontes de Nlíquido (N-28 e N-30) apresentaram um menor número de colmos (em torno de $25 \%$ ) em relação à ureia, que é a fonte preferencialmente utilizada na cultura do arroz, na avaliação realizada aos 25DAE (Tabela 2). O menor

Tabela 2 - Colmos por planta, índice SPAD, estatura (E) de plantas, número de panículas (NP) por $\mathrm{m}^{2}$, número de grãos por panícula (NGP), massa de mil grãos (MMG) e produtividade de grãos (PROD) em resposta a aplicação de diferentes fertilizantes nitrogenados no arroz irrigado, safra 2007/08. Santa Maria, 2010.

\begin{tabular}{|c|c|c|c|c|c|c|c|c|c|}
\hline \multirow{2}{*}{ Trat } & \multicolumn{2}{|c|}{-----Colmos por planta----- } & \multicolumn{2}{|c|}{-------Leituras SPAD------- } & \multirow{2}{*}{$\mathrm{E}(\mathrm{cm})$} & \multirow{2}{*}{$\mathrm{NP}\left(\mathrm{m}^{2}\right)$} & \multirow{2}{*}{ NGP } & \multirow{2}{*}{ MMG } & \multirow{2}{*}{$\begin{array}{l}\text { PROD } \\
\left(\mathrm{kg} \mathrm{ha}^{-1}\right)\end{array}$} \\
\hline & 25DAE & 46DAE & 54DAE & 82DAE & & & & & \\
\hline $\mathrm{T}^{*}{ }^{*}$ & $1,6 b^{1}$ & $1,7 \mathrm{~b}$ & $32,4 \mathrm{~b}$ & $31,7^{\mathrm{ns}}$ & $85,8^{\mathrm{ns}}$ & $339 \mathrm{~b}$ & $74 d$ & $26,4^{\mathrm{ns}}$ & $9.542^{\mathrm{ns}}$ \\
\hline $\mathrm{T} 2$ & $2,3 b$ & $2,0 \mathrm{~b}$ & $33,9 \mathrm{ab}$ & 32,7 & 84,5 & $368 b$ & $78 \mathrm{~d}$ & 26,5 & 10.968 \\
\hline $\mathrm{T} 3$ & $3,3 \mathrm{a}$ & $2,7 \mathrm{a}$ & 36,6 a & 32,3 & 88,9 & $410 \mathrm{a}$ & $114 \mathrm{a}$ & 27,6 & 9.829 \\
\hline $\mathrm{T} 4$ & $3,4 \mathrm{a}$ & $2,3 \mathrm{a}$ & $36,4 \mathrm{a}$ & 33,2 & 86,7 & $442 \mathrm{a}$ & $116 \mathrm{a}$ & 27,5 & 10.346 \\
\hline T5 & $3,8 \mathrm{a}$ & $2,5 \mathrm{a}$ & $35,5 \mathrm{ab}$ & 33,2 & 86,4 & $464 \mathrm{a}$ & $96 b$ & 26,8 & 10.403 \\
\hline T6 & $2,8 \mathrm{a}$ & $2,2 \mathrm{a}$ & $35,0 \mathrm{ab}$ & 33,0 & 87,1 & $407 \mathrm{a}$ & $89 \mathrm{c}$ & 25,1 & 10.347 \\
\hline $\mathrm{T} 7$ & $2,5 \mathrm{~b}$ & $2,1 \mathrm{~b}$ & $34,0 \mathrm{ab}$ & 33,0 & 84,4 & $400 \mathrm{a}$ & $80 \mathrm{~d}$ & 25,1 & 9.960 \\
\hline $\mathrm{T} 8$ & $3,2 \mathrm{a}$ & $2,4 \mathrm{a}$ & $37,3 \mathrm{a}$ & 33,2 & 86,6 & $427 \mathrm{a}$ & $70 \mathrm{~d}$ & 25,5 & 9.886 \\
\hline T9 & $3,5 \mathrm{a}$ & $2,3 \mathrm{a}$ & $36,1 \mathrm{a}$ & 32,8 & 88,7 & $357 \mathrm{a}$ & $87 \mathrm{c}$ & 26,7 & 10.124 \\
\hline $\mathrm{T} 10$ & $3,7 \mathrm{a}$ & $2,4 \mathrm{a}$ & $35,5 \mathrm{ab}$ & 34,0 & 86,8 & $457 \mathrm{a}$ & $84 c$ & 25,0 & 9.914 \\
\hline $\mathrm{T} 11$ & $4,2 \mathrm{a}$ & $2,5 \mathrm{a}$ & $37,0 \mathrm{a}$ & 34,1 & 88,9 & $443 a$ & $75 \mathrm{~d}$ & 26,5 & 10.431 \\
\hline $\mathrm{T} 12$ & $2,7 b$ & $2,1 \mathrm{~b}$ & $33,9 \mathrm{ab}$ & 33,7 & 87,0 & $347 \mathrm{~b}$ & $91 \mathrm{c}$ & 26,3 & 10.569 \\
\hline $\mathrm{T} 13$ & $2,7 b$ & $1,9 \mathrm{~b}$ & $34,1 \mathrm{ab}$ & 33,8 & 86,9 & $460 \mathrm{a}$ & $73 d$ & 26,4 & 10.505 \\
\hline Média & 21,9 & 14 & 30,1 & 33,1 & 86,85 & 410 & 92,2 & 26,4 & 10.157 \\
\hline $\begin{array}{l}\text { CV } \\
(\%)\end{array}$ & 3,09 & 2,26 & 3,6 & 3,4 & 2,41 & 11,8 & 17,4 & 4,4 & 6,9 \\
\hline
\end{tabular}

*Testemunha (T1), N líquido (N-30) com aplicação em R1 (T2), inibidor de urease com aplicação em R1 (T3), ureia com aplicação em R1 (T4), sulfato de amônio com aplicação em R1 (T5), ureia + enxofre (T6), N líquido (N-30) sem aplicação em R1 (T7), inibidor de urease sem aplicação em R1 (T8), ureia sem aplicação em R1 (T9), sulfato sem aplicação em R1 (T10), ureia + enxofre sem aplicação em R1 (T11), N líquido (N-28) sem aplicação em R1 (T12) e N líquido (N-28) com aplicação em R1 (T13); Valores seguidos pela mesma letra diferem entre si pelo teste de Tukey $(\mathrm{P} \leq 0,05) ;{ }^{\text {ns }}$ Médias não significativas pelo Teste $\mathrm{F}(\mathrm{P} \leq 0,05)$.

Ciência Rural, v.41, n.12, dez, 2011. 
número de colmos por planta parece estar atrelado a um efeito fitotóxico do $\mathrm{N}$ pulverizado na parte aérea das plantas, o qual causou queimaduras no tecido foliar em função da elevada dose utilizada $\left(70 \mathrm{~kg} \mathrm{ha}^{-1}\right)$ de $\mathrm{N}$ em V4. Comparando a testemunha com a ureia, houve um estímulo de $53 \%$ e $26 \%$ na emissão de colmos aos 25 e 46 DAE, respectivamente. Em relação às demais fontes utilizadas, houve diferenças apenas entre a testemunha.

Em relação ao monitoramento do estado nutricional das plantas através do índice SAPD, as maiores diferenças foram entre a testemunha e os demais tratamentos aos 54DAE. A ureia comum e recoberta com inibidor de urease proporcionou os maiores valores de índice SPAD aos 54DAE, não sendo detectada nenhuma diferença aos 82DAE.

Para os parâmetros avaliados na précolheita, nenhuma diferença foi detectada para estatura de plantas, porém, em relação ao número de panículas (NP), diferenças foram observadas para os fertilizantes fluidos, o qual foi prejudicado nesses tratamentos em função dos sintomas iniciais de fitotoxicidade, permanecendo os efeitos até o momento da colheita.

A aplicação ou não das diferentes fontes no estádio R1 determinou diferenças entre os tratamentos para o número de grãos por panícula. Com aplicação neste estádio houve maior número de grãos em cada panícula, pois é nesse momento de desenvolvimento que a absorção de $\mathrm{N}$ contribui pra a produção de espiguetas e para o enchimento de grãos (MAE, 1997), mesmo não havendo sido detectadas diferenças em relação ao $\mathrm{N}$ na planta.

Embora encontrando diferenças iniciais, essas não foram expressas em produtividade de grãos, uma vez que não houve diferenças entre tratamentos, inclusive no tratamento testemunha. Segundo MARZARI et al. (2005), a resposta da planta em crescimento vegetativo tem sido relacionada à quantidade de $\mathrm{N}$ aplicada para o arroz, o que reflete maior disponibilidade do nutriente, mas sua correspondente transformação em rendimento de grãos nem sempre tem sido obtida, o que pode estar relacionado com a perda de capacidade de utilização da radiação solar pelo auto-sombreamento das folhas e aumento da suscetibilidade a doenças fúngicas.

\section{Safra 2008/09}

Na segunda safra, o crescimento vegetativo do arroz novamente foi influenciado negativamente pelos fertilizantes fluidos, com um menor número de colmos por planta, aos 24 e 52DAE (Tabela 3). Com isso, evidencia-se se que a dose de utilização desses

Tabela 3 - Colmos por planta, índice SPAD, estatura (E) de plantas, número de panículas (NP) por m², número de grãos por panícula (NGP), massa de mil grãos (MMG) e produtividade de grãos (PROD) em resposta a aplicação de diferentes fertilizantes nitrogenados no arroz irrigado, safra 2008/09. Santa Maria, 2010.

\begin{tabular}{|c|c|c|c|c|c|c|c|c|c|}
\hline \multirow{2}{*}{ Trat } & \multicolumn{2}{|c|}{-----Colmos por planta----- } & \multicolumn{2}{|c|}{------Leituras SPAD------ } & \multirow{2}{*}{$\mathrm{E}(\mathrm{cm})$} & \multirow{2}{*}{$\mathrm{NP}\left(\mathrm{m}^{2}\right)$} & \multirow{2}{*}{ NGP } & \multirow{2}{*}{ MMG } & \multirow{2}{*}{$\begin{array}{l}\text { PROD } \\
\left(\mathrm{kg} \mathrm{ha}^{-1}\right)\end{array}$} \\
\hline & 25DAE & 46DAE & 54DAE & 82DAE & & & & & \\
\hline $\mathrm{T}^{*}$ & $2,0 b^{1}$ & $1,7 \mathrm{~b}$ & $29,8^{\mathrm{ns}}$ & $31,8 \mathrm{~b}$ & $74,4 \mathrm{~b}$ & $399 \mathrm{c}$ & $95^{\mathrm{ns}}$ & $25,8^{\mathrm{ns}}$ & $8.113 \mathrm{~b}$ \\
\hline $\mathrm{T} 2$ & $1,6 \mathrm{~b}$ & $1,8 \mathrm{~b}$ & 31,8 & $32,9 \mathrm{~b}$ & $73,9 b$ & $392 \mathrm{c}$ & 82 & 25,5 & $8.293 \mathrm{~b}$ \\
\hline $\mathrm{T} 3$ & $2,4 \mathrm{a}$ & $2,1 \mathrm{a}$ & 29,7 & $35,2 \mathrm{a}$ & 80,3 a & 545 & 91 & 26,3 & $10.178 \mathrm{a}$ \\
\hline $\mathrm{T} 4$ & $2,5 \mathrm{a}$ & $2,1 \mathrm{a}$ & 31,6 & $33,3 \mathrm{a}$ & $77,6 \mathrm{a}$ & $546 \mathrm{a}$ & 95 & 24,3 & $11.028 \mathrm{a}$ \\
\hline $\mathrm{T} 5$ & $2,5 \mathrm{a}$ & $2,4 \mathrm{a}$ & 29,6 & $33,8 \mathrm{a}$ & $79,1 \mathrm{a}$ & $510 \mathrm{~b}$ & 103 & 25,4 & $9.439 \mathrm{a}$ \\
\hline $\mathrm{T} 6$ & $2,6 \mathrm{a}$ & $2,0 \mathrm{a}$ & 29,7 & $33,7 \mathrm{a}$ & $79,5 \mathrm{a}$ & $458 \mathrm{~b}$ & 89 & 25,2 & $9.958 \mathrm{a}$ \\
\hline $\mathrm{T} 7$ & $1,9 b$ & $1,9 b$ & 29,0 & $33,2 \mathrm{a}$ & $73,1 \mathrm{~b}$ & $482 \mathrm{c}$ & 103 & 24,1 & $8.162 \mathrm{~b}$ \\
\hline $\mathrm{T} 8$ & $2,7 \mathrm{a}$ & $2,3 \mathrm{a}$ & 29,1 & $32,6 \mathrm{~b}$ & $78,9 \mathrm{a}$ & $420 \mathrm{~b}$ & 103 & 25,5 & $9.825 \mathrm{a}$ \\
\hline T9 & $2,6 \mathrm{a}$ & $2,1 \mathrm{a}$ & 30,3 & $32,5 \mathrm{~b}$ & $81,0 \mathrm{a}$ & $485 \mathrm{~b}$ & 94 & 25,5 & $10.533 a$ \\
\hline $\mathrm{T} 10$ & $2,0 \mathrm{a}$ & $2,0 \mathrm{a}$ & 31,0 & $31,4 \mathrm{~b}$ & $76,4 \mathrm{~b}$ & $464 b$ & 90 & 26,0 & $9.177 \mathrm{a}$ \\
\hline $\mathrm{T} 11$ & $2,2 \mathrm{a}$ & $2,2 \mathrm{a}$ & 29,8 & $32,3 \mathrm{~b}$ & $77,6 \mathrm{a}$ & $436 \mathrm{~b}$ & 93 & 25,0 & $9.492 \mathrm{a}$ \\
\hline $\mathrm{T} 12$ & $1,7 \mathrm{~b}$ & $1,85 \mathrm{~b}$ & 30,1 & $31,7 \mathrm{~b}$ & $73,4 \mathrm{~b}$ & $390 \mathrm{c}$ & 88 & 26,8 & $8.005 \mathrm{~b}$ \\
\hline $\mathrm{T} 13$ & $1,9 b$ & $1,88 \mathrm{~b}$ & 29,7 & $32,7 \mathrm{~b}$ & $76,5 \mathrm{~b}$ & $429 \mathrm{~b}$ & 85 & 24,8 & $8.310 \mathrm{~b}$ \\
\hline Média & 2,32 & 17,44 & 30,1 & 32,7 & 77,7 & 450 & 94 & 25,4 & 9.211 \\
\hline $\mathrm{CV}(\%)$ & 15,05 & 2,09 & 3,6 & 4,2 & 3,9 & 7,89 & 14,0 & 4,10 & 7,5 \\
\hline
\end{tabular}

*Testemunha (T1), N líquido (N-30) com aplicação em R1 (T2), inibidor de urease com aplicação em R1 (T3), ureia com aplicação em R1 (T4), sulfato de amônio com aplicação em R1 (T5), ureia + enxofre (T6), N líquido (N-30) sem aplicação em R1 (T7), inibidor de urease sem aplicação em R1 (T8), ureia sem aplicação em R1 (T9), sulfato sem aplicação em R1 (T10), ureia + enxofre sem aplicação em R1 (T11), N líquido (N-28) sem aplicação em R1 (T12) e N líquido (N-28) com aplicação em R1 (T13); ${ }^{1 /}$ Valores seguidos pela mesma letra diferem entre si pelo teste de Tukey $(\mathrm{P} \leq 0,05) ;{ }^{\text {ns }}$ Médias não significativas pelo Teste $\mathrm{F}(\mathrm{P} \leq 0,05)$. 
fertilizantes deverá ser calibrada previamente para o uso na cultura do arroz irrigado.

O monitoramento do estado nutricional através do índice SPAD apontou diferenças entre as fontes apenas após a aplicação suplementar em R1. Porém, aqui, podem-se fazer algumas considerações: a aplicação de ureia, sulfato de amônio e inibidor de urease proporcionaram maior crescimento vegetativo, evidenciado pela resposta do número de colmos provocando um efeito de diluição, associado com a remobilização do $\mathrm{N}$ das folhas maduras (fonte) para partes da planta em desenvolvimento (dreno), já que este é um elemento de alta mobilidade dentro da planta (TAIZ; ZEIGER, 2006). Soma-se a isso que as leituras do clorofilômetro são realizadas em folhas recentemente desenvolvidas, há menor probabilidade e/ou estas demoram mais tempo para expressar uma eventual deficiência de $\mathrm{N}$ da planta (POCOJESKI, 2007). Com isso, as diferenças entre as fontes somente foram expressas a partir do fornecimento do N, em R1.

Diferentemente do ano anterior, a produtividade de grãos diferiu estatisticamente entre os tratamentos. A testemunha, sem aplicação de N, obteve uma produtividade $25 \%$ menor que o tratamento ureia, semelhante aos fertilizantes fluidos N-28 e N-30 independente da aplicação suplementar de N em R1. Para as demais fontes, não houve diferenças estatísticas, inclusive em relação à aplicação do $\mathrm{N}$ suplementar, indicando que, para solos com características semelhantes ao que foi conduzido o experimento, essa aplicação não seria vantajosa. Para os demais componentes de produtividade, número de grãos por panículas e massa de mil grãos, nenhuma diferença entre os tratamentos foi diagnosticada.

\section{CONCLUSÃO}

As perdas de $\mathrm{N}$ após aplicação incorporada na semeadura são insignificantes e independem das fontes de $\mathrm{N}$ utilizadas. Após a aplicação no perfilhamento, o sulfato de amônio é a fonte menos suscetível às perdas por volatilização.

A ureia com inibidor de urease e o sulfato de amônio são eficientes em substituir a ureia na cultura do arroz irrigado, mas a resposta em relação à produtividade é variável entre os anos, estando atrelada a condições edafoclimáticas e seu uso condicionado à relação de custos do $\mathrm{N}$ aplicado.

\section{AGRADECIMENTOS}

À Fundação de Apoio à Pesquisa do Estado do Rio Grande do Sul (FAPERGS), pela bolsa de Iniciação Científica do Rio Grande do Sul a Mara Grohs, ao Conselho Nacional de
Desenvolvimento Científico e Tecnológico (CNPq), pela bolsa de Produtividade em Pesquisa a Enio Marchesan e Leandro Souza da Silva e de Iniciação científica a Rafael Bruck Ferreira e de apoio técnico a Gerson Meneghetti Sarzi Sartori, bem como financiamento do projeto.

\section{REFERÊNCIAS}

ARAÚJO, E. da S. et al. Calibração de câmara semi-aberta estática para quantificação de amônia volatilizada do solo. Pesquisa agropecuária brasileira, Brasília, v.44, n.7, p.769776. Disponível em: <http://www.scielo.br/pdf/pab/v44n7/ 18.pdf $>$. Acesso em: 27 set. 2011. doi: 10.1590/S0100204X2009000700018.

CHATURVEDI, I. Effect of nitrogen fertilizers on growth, yield and quality of hybrid rice (Oryza sativa). Journal of Central European Agriculture, European countries, v.6, n. 4, p.611-618, 2005. Disponível em: 〈hrcak.srce.hr/file/26779〉. Acesso em: 27 set. 2011.

COELHO A.M. et al. Eficiência agronômica do cloreto de amônio e bicarbonato de amônio como fontes de nitrogênio para a cultura do milho. Sete Lagoas, MG: Embrapa, 2006.

DUARTE, F.M. et al. Perdas de nitrogênio por volatilização de amônia com aplicação de ureia em solo de várzea com diferentes níveis de umidade. Ciência Rural, Santa Maria, v.37, n.3, p.705-711, 2007. Disponível em: <http://www.scielo.br/pdf/ cr/v37n3/a16v37n3.pdf>. Acesso em: 27 fev. 2011. doi: 10.1590/S0103-84782007000300016.

EMBRAPA. Centro Nacional de Pesquisa de Solos, Rio de Janeiro, RJ. Sistema brasileiro de classificação dos solos. Brasília: Embrapa-SPI, 2006. 306p.

HARRELL D. Timing is everything with nitrogen fertilizer applications. Rice Research Station News, Louisiana, v.4, n.2, p.1-2, 2007. Disponível em: <http://www.lsuagcenter.com/ MCMS/RelatedFiles/\% 7B 7E21E11E-FB 41-4A7C-809B90A317C22223\%7D/VOLUME+4+ISSUE+2.pdf >. Acesso em: 27 fev. 2011.

LARA CABEZAS, W.A.R. et al. Volatilização de N-NH na cultura de milho: I. Efeito da irrigação e substituição parcial da ureia por sulfato de amônio. Revista Brasileira de Ciência do Solo, Viçosa, v.21, p.481-487, 1997. Disponível em: <http:/ /sbcs.solos.ufv.br/solos/revistas/v21n3a19.pdf>. Acesso em: 27 set. 2011.

MAE, T. Physiological nitrogen efficiency in rice: Nitrogen utilization, photosynthesis, and yield potential. Plant and Soil, Crawley, v.196, p.201-210, 1997. Disponível em: <http:/ /www.springerlink.com/content/t2nk711u07q018x3/ fulltext.pdf>. Acesso em: 27 set. 2011.

MALHI, S.S. et al. Nitrogen fertilization management for notill cereal production in the Canadian great plains: a review. Soil \& Tillage Research, v.60, p.101-122, 2001.

MARTHA JÚNIOR, G. et al. Perda de amônia por volatilização em pastagem de capim-tanzânia adubada com ureia no verão. Revista Brasileira de Zootecnia, Viçosa, v.33, n.6, p.2240247, 2004. Disponível em: <http://www.scielo.br/pdf/rbz/ v33n6s3/23425.pdf>. Acesso em: 27 set. 2011.doi: 10.1590/ S1516-35982004000900009. 
MARZARI, V. et al. Épocas de aplicação do fertilizante nitrogenado no sistema convencional de semeadura de arroz irrigado. Ciência Rural, Santa Maria, v.35, n.5, p.11901193, 2005. Disponível em: <http://www.scielo.br/pdf/cr/ v35n5/a32v35n5.pdf>. Acesso em: 27 set. 2011. doi: 10.1590/ S0103-84782005000500032.

POCOJESKI, E. Estimativa do estado nutricional de arroz irrigado por alagamento. 2007. 97f. Dissertação (Mestrado em Ciência do Solo) - Universidade Federal de Santa Maria,Santa Maria, RS.
SOSBAI- SOCIEDADE SUL-BRASILEIRA DE ARROZ IRRIGADO. Arroz irrigado: recomendações técnicas da pesquisa para o Sul do Brasil. Santa Maria, RS: SOSBAI, 2007. $159 \mathrm{p}$.

TAIZ, L.; ZEIGER, E. Fisiologia vegetal. 3.ed. Porto Alegre: Artemed, 2006. 722p.

TEDESCO, M.J. Análise de solo, plantas e outros materiais. Porto Alegre: UFRGS, Depto. de Solos, Faculdade de Agronomia, 1995. 174p. 